Examination.-The patient presented a wasted appearance. Her skin was rough and shrunken, with a suggestive cachectic hue. There were no enlarged cervical, axillary or inguinal glands. The abdomen showed a bulging in the left upper quadrant about three inches to the left of the median line. There was a well-defined tumor apparently adherent to something; it did not feel nodular, but was very tender, and measured about 5 by $7 \mathrm{~cm}$. A test breakfast of toast and tea gave a total aeidity of 40, hydrochloric acid 22.5. Although seeds had been given the previous evening, none were present in the siphoned stomach contents, and the total quantity removed after fifty minutes' digestion did not exceed an ounce. When the stomach was dilated with a Seidlitz powder the lower border did not show a downward displacement, nor did the gas give her distress. Dr. J. N. Hall, seeing the case with me, gave a tentative diagnosis of early malignancy, probably on an old gastric ulcer, and an exploratory operation was advised and accepted.

Operation.-At St. Joseph's Hospital, June 20, 1908. Median incision in upper abdomen. The pylorus was unobstructed, and there were no adhesions anywhere about this end of the stomach or the gall bladder. A number of glands about the lesser curvature were indurated and the greater curvature of the stomach was adherent to the parietal peritoneum for about $7 \mathrm{~cm}$. from the Mikulicz-Hartmann line toward the cardiac end. The adhesions were from the mass, which was decidedly nodular; as large as a goose egg, and involving both the anterior and posterior surface of the stomach. To the pyloric side of this mass was a well-defined circular cicatrix which merged into the malignant tumor, thus showing conclusively its origin on the base of an old gastric ulcer. As there was no obstruction to the pylorus, and the tumor extended so fa: to the left (requiring practically a total gastrectomy) and in view of the associated glandular enlargement about the lesser curvature, it was considered to be an inoperable case and the abdomen was closed with silkworm sutures.

Postoperative History.-The patient was up in a chair in five days and out in a week, and is now eating more heartily and relishing her food better than she has for the past two years. This result has been accomplished by giving her the natural Carlsbad salts before meals, thereby reducing the hyperacidity and provoking several free evacuations daily. Recent reports (October 1) are that she has no pain from hyperacidity, is gaining in weight and eating well. There is, however, the early appearance of inguinal adenitis on the right side. This I believe to be one of those lost opportunities previously referred to, for had she been given the benefit of an early exploratory operation eighteen months ago, an excision of the ulcer-bearing area would no doubt have spared her the present hopeless life as a victim of malignant disease.

\section{BELLADONNA POISONING.}

\section{IRVING WILSON VOORHEES, M.S., M.D.} NEW YORK.

Patient.-May 27, 1908, I was called to see W. B., male, aged 29.

History.--The patient complained of inpaired vision and felt certain that he was becoming blind. 'The difficulty had increased progressively for twenty-foux hours, during which time he had been unable to read written or printed matter; he had also been obliged to give up his work at his office. Previous to this he had been well except for a slight pain in his right side and declared that he had not taken medicine of any kind for a year.

Examination.--l3oth pupils were greatly dilated. They were equal in size but did not react to either light or accommodation. The eye-groumds were normal. The mouth and throrat were dry and parched; the pulse was rapid and irregular and the skin dry like parchment. The patient was very nervous and seemed greatly worried about his condition. In reply to questions he stated that for several days he had been wearing a porous plaster on the right side because of a "stitching pain in the liver," and that he had also rubbed this area' with $a$ "patent medicine" for two days before applying the plaster.

Treatment.-The plaster was removed with some difliculty; the true skin was exposed beneath the plaster and for some distance around it. I prescribed physostigmin sulphate for the eyes and gave morphin sulphate, $1 / 8$ grain, hypodermatically, The patient was put to bed and was well in twenty-four hours.

I am told that the condition is not at all uneommon, but I have never seen it reported.

3544 Broadway.

\section{A NEW STYYLE TONSIL FORCEPS.}

\section{ERNEST MORAIVECK', M.D. LOUISVILLE, KY.}

The advantages of the instrument here shown over other similar instruments are as follows: The blades or teeth are so constructed that they grasp a considerable portion of the tonsil, but do not tend either to crush off or tear out the grasped portion; consequently, having once engaged the tonsil they remain in place from the

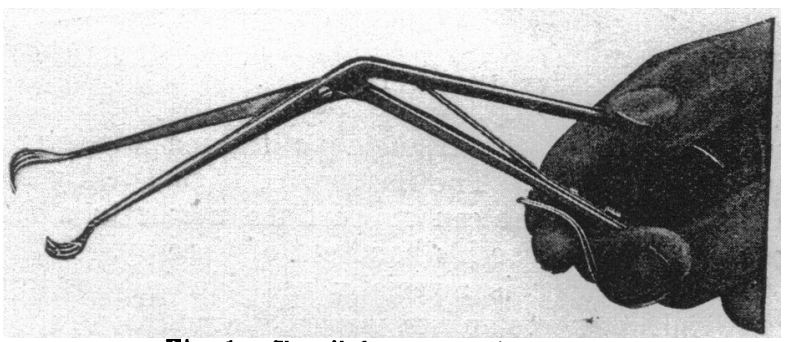

Fig. 1.--Tonsil forceps ready for use.

beginning to the end of the operation, even in case of a very friable tonsil. The extreme lightness of the instrument, its small size, and the bend of the handles insure its remaining in position throughout the operation without either dragging unduly on the tonsil by its weight, or interfering with the manipulations of the operator. Scissors, knives or dissecting instruments of any kind may be used around it with the greatest ease. It interferes in no way with the patient's comfort.

A tonsillotome or the loop of a wire snare, no matter how small, can always be introduced over it, either over

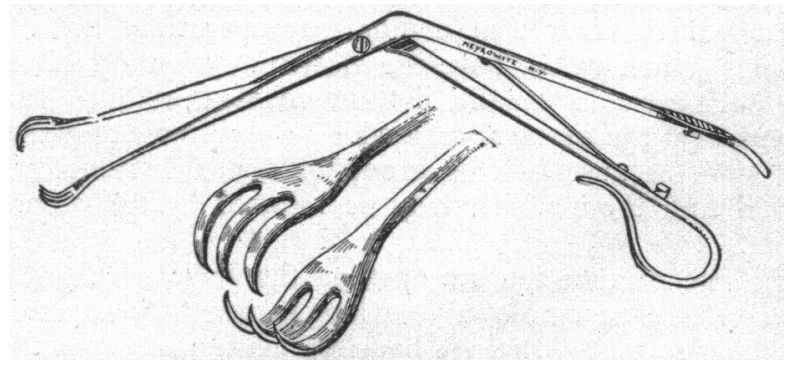

Fig. 2.-Details of tonsll forceps

the whole finger-end at once, or, in case of a very small loop, by introducing it through and around the open handle of the instrument. In the latter case, it is only necessary to bear in mind the position the loop of the snare will occupy after it has made the complete turn that will, of course, result from its introduction in this manner.

A more secure hold on the tonsil usually can be obtained by introducing the instrument diagonally across the tongue; that is to say, for the right tonsil the forceps should be introduced from the left side of the mouth, and vice versa. Once, however, the tonsil is grasped 